\title{
New pneumococcal conjugate vaccine introductions in four sub-Saharan African countries: a cross-country analysis of health systems' impacts
}

\author{
Sergio Torres-Rueda ${ }^{1}$, Helen ED Burchett ${ }^{1}$, Ulla K Griffiths ${ }^{1}$, Pierre Ongolo-Zogo ${ }^{2}$, \\ Jean-Marie Edengue ${ }^{3}$, Yayehyirad Kitaw ${ }^{4}$, Mitike Molla ${ }^{5}$, Lawrence Gelmon ${ }^{6,8}$, \\ Washington Onyango-Ouma ${ }^{6}$, Mamadou Konate ${ }^{7}$, Sandra Mounier-Jack ${ }^{1}$.
}

1. Department of Global Health and Development, London School of Hygiene and Tropical Medicine, London, UK

2. Centre for Development of Best Practices in Health, Yaoundé Central Hospital, Yaoundé, Cameroon

3. Ministry of Health, Yaoundé, Cameroon

4. Independent consultant, Addis Ababa, Ethiopia

5. Addis Ababa University, Addis Ababa, Ethiopia

6. University of Nairobi, Nairobi, Kenya

7. Independent consultant, Bamako, Mali

8. University of Manitoba, Manitoba, Canada

\begin{abstract}
Background: Pneumonia is a main cause of under-five mortality in low-income settings. The pneumococcal conjugate vaccine (PCV) has been introduced in many countries as a tool in the disease's prevention. Although PCV's effectiveness has been established, less is known about the effects of introducing additional injectable vaccines into routine immunisation programmes, particularly in the context of resource-constrained settings.

Objectives: To explore the effects of PCV introduction on the immunisation programmes and health systems in four low-income countries.

Methods: This study was carried out in Cameroon, Ethiopia, Kenya and Mali. Three to four regions and nine to 10 districts were selected within each country. Semi-structured interviews were carried out at national, regional and district levels $(\mathrm{n}=173)$. Researcher-administered questionnaires were completed with facility staff $(\mathrm{n}=124)$. Routine data on monthly vaccination activities were collected at district and facility levels.

Results: PCV was generally well integrated into existing routine immunisation. Little or no impact was found in most areas of the health systems. Some minor effects were found on immunisation programmes, particularly in areas with either planning activities or investments e.g. staff skills were strengthened and there were limited improvements in surveillance. Although health sector workers perceived increases in the coverage of other vaccines following the introduction of PCV, routine service data did not confirm this claim. No substantial impacts were seen in health system management, service delivery or performance.
\end{abstract}

Conclusions: The introduction of PCV had marginal impacts on the Expanded Programme for Immunisation and little to none on broader health systems.

Keywords: pneumococcal conjugate vaccine, sub-Saharan, health systems' impacts.

DOI: http://dx.doi.org/10.4314/ahs.v15i3.22

Cite as: Torres-Rueda S, Burchett HED, Griffiths UK, Ongolo-Zogo P, Edengue J-M, Kitaw Y, Molla M, Gelmon L, Onyango-Ouma W, Konate M, Mounier-Jack S. New pneumococcal conjugate vaccine introduction in four sub-Saharan African countries: a cross-country analysis of bealth systems' impacts. Afri Health Sci. 2015;15(3):868-77. doi: http:/ / dx.doi.org/10.4314/ahs.v15i3.22

\section{Introduction}

\section{Corresponding author:}

Sergio Torres-Rueda

Department of Global Health and Development

London School of Hygiene and Tropical Medicine

15-17 Tavistock Place

London WC1H 9SH, UK

Email: sergio.torresrueda@1shtm.ac.uk

Telephone: +44 (0)207958 8310

Fax: +44 (0)20 79272701
Pneumonia is a main cause of under-five mortality in low-income countries around the world; an estimated 540,000 children died from the disease in 2010 in sub-Saharan Africa ${ }^{1}$. The Streptococcus pneumoniae bacterium is a major cause of pneumonia ${ }^{2}$, and of other illnesses such as meningitis ${ }^{3}$. The effectiveness of pneumococcal conjugate vaccines (PCV) in preventing pneumonia has been established ${ }^{4,5}$ and the World Health Organization recommends the adoption of PCV into vaccination programmes in developing countries with high pneumonia mortality rates ${ }^{6}$. With Gavi Alliance 
support, over 25 countries introduced PCV since 2010 and as many as 50 others had been approved for introduction by October $2014^{7}$.

Children are offered three doses of PCV at the same time as the diphtheria-tetanus-pertussis, hepatitis B, Haemophilius influenzae type $b$ vaccine (pentavalent vaccine). PCV13 is offered in one-dose vials whilst PCV10 is provided in two-dose vials without preservative, raising concerns about the risk of Adverse Events Following Immunisations (AEFIs) when first introduced in low-income settings ${ }^{8}$.

As more vaccines are added to routine immunisation schedules, questions have been raised regarding whether Expanded Programmes on Immunisation (EPI) would become overburdened. Previous studies either focused on demonstrating the health impact of $\mathrm{PCV}^{4,5,9-11}$, or explored how new vaccines affected specific health system functions or vaccination coverage $e^{12,13}$. No research has evaluated the effects of adding PCV into EPI nor how it, as one component of the Integrated Global Action
Plan for the Prevention and Control of Pneumonia and Diarrhoea ${ }^{14}$, may have affected wider health systems.

This paper aims to explore the impact of PCV introductions on EPI and health systems in four countries in sub-Saharan Africa. The research was part of a larger study, exploring the impact of introducing four vaccines in six low- and middle-income countries ${ }^{15}$.

\section{Methods}

Cameroon, Ethiopia, Kenya and Mali were selected because they were early adopters of PCV (Table 1).

See Table 2 for background information on each country.

Data collection started between 5-13 months following introduction. Three to four regions were chosen in each country based on vaccination coverage (low, average and high compared to a national average). In Ethiopia four regions were selected to cover the range of health administration directorates (urban, agrarian and pastoral) as well as remote areas (Table 3 ).

Table 1: PCV introduction characteristics

\begin{tabular}{|c|c|c|c|c|c|c|}
\hline Country & $\begin{array}{l}\text { PCV } \\
\text { type }\end{array}$ & $\begin{array}{l}\text { Date of vaccine } \\
\text { introduction }\end{array}$ & Data collection period & Introduction strategy & Catch up strategy & Other relevant features \\
\hline Cameroon & PCV13 & July 2011 & May - June 2012 & Across the whole country at once & $\begin{array}{l}\text { None, but lack of } \\
\text { understanding led some } \\
\text { regions to vaccinate outside of } \\
\text { the target group }\end{array}$ & $\begin{array}{l}\text { Upgraded cold chain using French debt relief programme funding. } \\
\text { Pentavalent changed from } 2 \text { to } 10 \text { dose vial in March } 2011 \text {. } \\
\text { Meningitis A vaccination campaigns conducted in some regions in } 4^{\text {th }} \text { quarter } 2011 \text { (not } \\
\text { in study regions). } \\
\text { Introduction occurred at a time of suspension of GAVI Alliance's reward for } \\
\text { performance. }\end{array}$ \\
\hline Ethiopia & PCV10 & November 2011 & $\begin{array}{l}\text { December } 2012 \text { - } \\
\text { January } 2013\end{array}$ & Across the whole country at once & All $<1$ year old & $\begin{array}{l}\text { Health information systems were being reconfigured at time of introduction. } \\
\text { Integrated Management of Childhood Illness training carried out a few months prior to } \\
\text { introduction. }\end{array}$ \\
\hline Kenya & PCV10 & February 2011 & $\begin{array}{l}\text { July - August 2011; } \\
\text { March - April 2012 }\end{array}$ & Across the whole country at once & All $<1$ year old & $\begin{array}{l}\text { Additional health workers recruited (before and after introduction). } \\
\text { Ongoing modernisation of cold chain. } \\
\text { Reach Every District data quality trainings carried out (shortly before introduction). } \\
\text { Pentavalent changed from } 2 \text { to } 10 \text { dose vials around the time of the PCV introduction. } \\
\text { Polio and measles outbreaks led to vaccination campaigns during PCV planning. }\end{array}$ \\
\hline Mali & PCV13 & $\begin{array}{l}\text { March- } \\
\text { December } 2011\end{array}$ & $\begin{array}{l}\text { March - June 2011; } \\
\text { January } 2012\end{array}$ & $\begin{array}{l}\text { Phased over } 9 \text { months (March to } \\
\text { November 2011) }\end{array}$ & No catch up & $\begin{array}{l}\text { Numerous health campaigns conducted (14 in } 2010 \text { and } 11 \text { in 2011). } \\
\text { Political unrest from March } 2012 \text {. } \\
\text { Introduced meningococcal A vaccine through campaigns around the same time as PCV. }\end{array}$ \\
\hline
\end{tabular}


Table 2: Countries' health and vaccination indicators

\begin{tabular}{|l|l|l|l|l|}
\hline Country & $\begin{array}{l}\text { Under-5 } \\
\text { mortality per } \\
\text { 1000 live } \\
\text { births (2011) }\end{array}$ & $\begin{array}{l}\text { \% of under-5 } \\
\text { deaths due to } \\
\text { pneumonia } \\
\mathbf{( 2 0 1 0 )}^{\mathbf{2 7}}\end{array}$ & $\begin{array}{l}\text { DTP3 } \\
\text { coverage (\% } \\
\text { one-year } \\
\text { old } \\
\text { children) } \\
\mathbf{( 2 0 1 1 )}^{\mathbf{2 8}}\end{array}$ & $\begin{array}{l}\text { Health } \\
\text { expenditure, } \\
\text { total (\% of } \\
\text { GDP) (2011) }\end{array}$ \\
\hline Cameroon & 101 & 22 & 82 & 5.4 \\
\hline Ethiopia & 71 & 22 & 65 & 4.1 \\
\hline Kenya & 76 & 20 & 88 & 4.4 \\
\hline Mali & 132 & 24 & 72 & 6.8 \\
\hline
\end{tabular}

Table 3: Data collected in each study country

\begin{tabular}{|c|c|c|c|c|c|}
\hline Country & $\begin{array}{l}\text { National } \\
\text { interviewees }\end{array}$ & $\begin{array}{l}\text { Regional } \\
\text { interviewees } \\
\text { (Number of } \\
\text { regions) }\end{array}$ & $\begin{array}{l}\text { District } \\
\text { interviewees }\end{array}$ & $\begin{array}{l}\text { Total number } \\
\text { of } \\
\text { interviewees }\end{array}$ & $\begin{array}{l}\text { Facility } \\
\text { questionnaires }\end{array}$ \\
\hline Cameroon & 10 & $\begin{array}{l}14 \\
(3)\end{array}$ & $\begin{array}{l}23 \\
(9)\end{array}$ & 47 & 28 \\
\hline Ethiopia & 8 & $\begin{array}{l}4 \\
(4)\end{array}$ & $\begin{array}{l}11 \\
(10)\end{array}$ & 23 & 26 \\
\hline Kenya & 14 & $\begin{array}{l}11 \\
(3)\end{array}$ & $\begin{array}{l}26 \\
(9)\end{array}$ & 51 & 43 \\
\hline Mali & 16 & $\begin{array}{l}8 \\
(3)\end{array}$ & $\begin{array}{l}28 \\
(9)\end{array}$ & 52 & 27 \\
\hline TOTAL & 48 & $\begin{array}{l}37 \\
(13)\end{array}$ & $\begin{array}{l}88 \\
(37)\end{array}$ & 173 & 124 \\
\hline
\end{tabular}

Two to three districts were selected per region based on vaccination coverage and to represent a spectrum of urbanisation and rurality. Health facilities were selected based on increasing distance from the district centre. We aimed to sample at least three facilities per district, although more were sampled in Kenya districts and fewer in some Ethiopian districts. (Table 3). Government, private and faith-based health facilities were included.

A mixed methods approach was used, including interviews, questionnaires and the collection of routine health service data. Semi-structured interviews were carried out with 173 key informants including EPI staff and health service managers at national, regional and district levels who had been involved in, or were knowledgeable of, the PCV introduction. Researcher-administered questionnaires were completed with vaccination staff in 124 facilities (see Table 3).

Interviews were recorded, transcribed and, when necessary, translated. Routine data was collected on monthly PCV and pentavalent vaccine uptake from facilities and districts.

An adaptation of the WHO's health systems building blocks framework ${ }^{16,17}$ was used to structure the data collection tools. However the findings will be presented according to a framework adapted from the World Health Report $2000^{18}$, since this was felt to be more ac- 
tionable for countries introducing PCV or similar vaccines, as well as providing a more holistic perspective of health systems levers (inputs, management, delivery, and performance $)^{19}$. The questionnaire was adapted from the post introduction evaluation methodology ${ }^{20}$. Semi-structured interviews were analysed using thematic content analysis with the software 'Open Code"21. Questionnaire data was analysed using descriptive statistics in SPSS software. Segmented regression analyses were conducted on the routine data to test statistical significance of changes in trends of utilisation of other vaccinations following the introduction ${ }^{22}$.

Ethical approval was obtained from LSHTM and relevant national research ethics committees in each study country. Signed consent was obtained prior to data collection.

\section{Results}

PCV was generally well integrated into existing routine immunisation in study countries. Some interviewees explained that because PCV was added to the routine vaccination programme (as opposed to delivered through campaigns), it had an inherently positive impact, providing more focus on EPI. Little or no impact was found in most health system areas. Some minor and short-term effects were found on the immunisation programmes. These are discussed in more detail below.

\section{Effects on health system inputs}

The introduction had no effect on most inputs. Some positive effects were reported, particularly in staff strengthening and financial resource availability. Minor and temporary negative effects were found in staff workload and cold chain availability.

\section{Staff}

Informants reported no changes in the number and distribution of staff during and following the PCV introductions. The proportion of facility respondents reporting temporarily increased workload ranged from $46 \%$ in Ethiopia to $93 \%$ in Kenya. Reasons for this included; increased demand and greater time spent on sensitisation activities. There were also varying perceptions on whether time spent on general vaccination activities since introduction had increased; from $12 \%$ in Ethiopia to 63\% in Cameroon (Table 4).

\section{Cold chain}

Interviewees reported that existing cold chain was sufficient to accommodate PCV. Some explained that prior cold chain assessments and improvements had been critical to facilitate the introduction. Overall, key informants in Mali, Ethiopia and Cameroon (and 74\% of facility respondents across the four countries) said they coped with additional cold chain requirements. Some difficulties with cold chain were reported at district levels in Mali and Cameroon, and at regional level in Ethiopia. These problems were resolved with adaptive strategies, such as more frequent deliveries from the regional level, or facilities picking up the vaccines from the district cold store on the delivery day.

Some stock-outs of PCV were reported in the first 1-3 months after introduction. These were likely due to unclear directives on planning around catch-up strategies and target populations; initially some facilities reportedly gave out the vaccine to infants beyond the age range which had been planned for, depleting existing stocks quickly. The proportion of facilities reporting stockouts varied: 8\% in Ethiopia, 25\% in Mali, 39\% in Cameroon and $51 \%$ in Kenya. The introductions were not thought to have caused stock-outs of other vaccines.

Table 4: Perceived changes in workload

\begin{tabular}{|l|l|l|l|l|}
\hline & Cameroon & Ethiopia & Kenya & Mali \\
\hline $\begin{array}{l}\text { \% of facility respondents who reported experiencing } \\
\text { temporary increases in workload around the time of } \\
\text { introduction }\end{array}$ & 60 & 46 & 93 & 52 \\
\hline $\begin{array}{l}\text { \% of facility respondents who felt time spent on } \\
\text { vaccination activities increased since PCV was } \\
\text { introduced }\end{array}$ & 63 & 12 & 43 & 48 \\
\hline
\end{tabular}


Changes in the presentation of the pentavalent vaccine (from 2-dose to 10-dose vials) around the time of the PCV introductions created space for the new vaccines in Cameroon, Kenya and Mali.

\section{Financing}

Key informants in Mali, Ethiopia and Kenya reported substantial increases in domestic allocation of resources to support PCV introductions. No concrete effect on financing other health programmes was reported. Long-term financial sustainability was mentioned as a concern in Kenya, Cameroon and Ethiopia.

"With the new vaccines, the state will have to invest much more because these vaccines are expensive. The share of co-financing by the government increases with Gavi reducing its financing... that is why it is important to advocate for the government to continue to invest in the vaccination programme..." National-level interviewee, Cameroon

Introduction funds were generally deemed sufficient. However, in Mali interviewees speculated that financial constraints delayed implementation, resulting in a phased introduction. All countries allocated additional funds for training. Some minor additional transportation and social mobilisation costs for outreach were reported in Ethiopia and Cameroon at sub-national and facility levels, which were covered by local budgets.

\section{Skills}

Most interviewees and $75 \%$ of facility respondents said that training for PCV had strengthened staff skills, notably injection administration skills, knowledge of AEFIs and social mobilisation techniques. Key informants in all countries stated that training covered broader topics than PCV, acting as a general EPI refresher and, in Ethiopia, also covering pneumonia prevention. However, at the facility-level about half of respondents perceived the training to have been focused narrowly on PCV. The training was not reported to have disrupted routine activities.

\section{Effects on bealth system management}

There were largely no effects reported on management as a result of the PCV introduction. Some positive effects were seen in improved integration of EPI and pneumonia prevention in Ethiopia and, to a lesser extent, in regulatory processes in Kenya.

\section{Management and planning}

The planning processes for the introductions did not appear to have affected other health service activities in Cameroon, Ethiopia or Mali. In Kenya, the planning process coincided with a polio vaccination campaign following an outbreak, which was said to have created challenges because the same officers were needed for both activities. In Ethiopia there was alignment between PCV introduction planning activities and other health systems planning. Input from sub-national levels at the planning stage was reported in Ethiopia and Kenya. In Ethiopia the inter-agency coordination committee (ICC) was reported to have been strengthened by the introduction, notably because of active thematic sub-committees which continued to meet after PCV was introduced. There were no operational technical advisory committees on immunisation in the four countries at the time.

Limited involvement of stakeholders outside EPI was reported. There were some elements of an integrated approach to the control of pneumonia in Ethiopia, where interviewees mentioned specific collaboration between those planning Integrated Management of Childhood Illnesses (IMCI) strategies and EPI. A national IMCI training was implemented before the PCV introduction. In Mali a national integrated pneumonia control workshop was organised but not followed up. Some limited collaboration was reported between health promotion, HIV and EPI in Kenya.

There were no changes reported in the frequency or organisation of supervision. In Cameroon and Ethiopia additional supervisions were carried out in some regions immediately after the introductions. In Mali and Cameroon, targeted supervision activities were planned but not carried out because of lack of funds. Integrated supervision of immunisation and other primary care activities was the norm in all countries.

There were no major changes reported on the accuracy or timeliness of health information management systems apart from some initial delays in rolling out updated forms in all countries.

\section{Regulatory processes}

Changes to regulatory processes were reported by key informants in Kenya and Mali. In Kenya, the Pharmacy and Poisons Board was said to have been strengthened by the process of registering the new vaccine and was seen as beneficial for future introductions. On the contrary, the national regulatory process was bypassed in Mali which, some argued, undermined domestic licensing regulatory processes. 


\section{Effects on service delivery}

In general, service delivery was unchanged by the introductions. PCV was delivered as part of routine childhood immunisation services. Ninety-five percent of facility respondents stated that there had been no change in the number of vaccination sessions offered, $92 \%$ stated that the pattern of outreach vaccination sessions remained unchanged, and $85 \%$ explained that the type of service package delivered alongside vaccination services had not changed.

\section{Effects on health system performance}

In general, no effect was seen on health system performance, although some improvements in staff morale were reported.

\section{Health service coverage}

There was a stark contrast between perceptions of the effect of the new vaccine on uptake of other routine vaccines and findings from the routine data. Many key informants and $78 \%$ of health facility respondents perceived changes in the total number of children vaccinated for other diseases following the PCV introduction. These views were particularly strong in Kenya. However, segmented regression analyses of routine data showed no changes in the monthly number of children vaccinated with the first dose of the pentavalent vaccine in Kenya, Ethiopia and Cameroon before and after the introduction. An increase in coverage of the first dose of the pentavalent vaccine was initially observed in Mali, although only in the short term (see Figure 1).
Interviewees, and $54 \%$ of facility respondents, believed that offering PCV had enabled them to better trace vaccine defaulters.

"It strengthens the coverage of other vaccines... because when they were mobilising for PCV, it opened a door for finding defaulters when the health extension workers went house to house. So they bring them." District-level interviewee, Ethiopia

"We were able even to get children who...were not immunised with other vaccines because, as you know, in Kenya pneumonia is feared." District-level interviewee, Kenya

\section{Adverse Effects Following Immunisation reporting} Despite global interest in AEFIs related to PCV, as well as attention paid to surveillance and AEFI training, no changes in the number of registered AEFIs for any vaccine was reported. Some key informants explained that AEFIs were routinely underreported.

Many interviewees stated that the PCV introductions placed a strong emphasis on AEFI surveillance, particularly at the national level in Ethiopia and Kenya, where preservative-free PCV10 was introduced. The introduction was seen as a catalyst for AEFI surveillance in Ethiopia, where key informants mentioned that four sentinel sites were set up for a year post-introduction. In Cameroon, the PCV introduction resulted in additional funding for surveillance, including laboratory strengthening and training of laboratory staff.

\section{Vaccine acceptance}

All countries benefited from strong political support and social mobilisation activities during PCV introduction.

Figure 1: Number of children vaccinated with the first dose of the pentavalent vaccine before and after PCV introductions

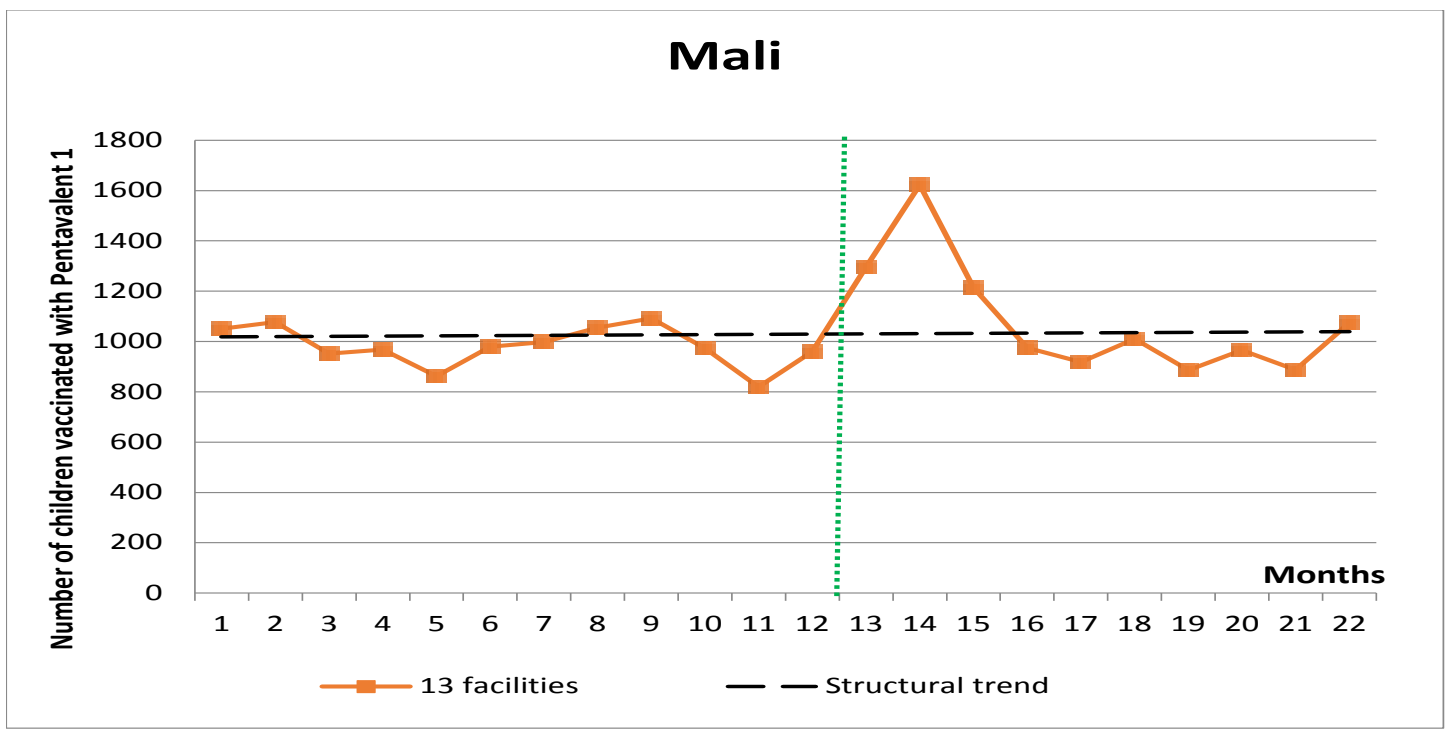

Note: The vertical dotted line shows the date when the new vaccine was introduced into the facility. 


\section{Cameroon}
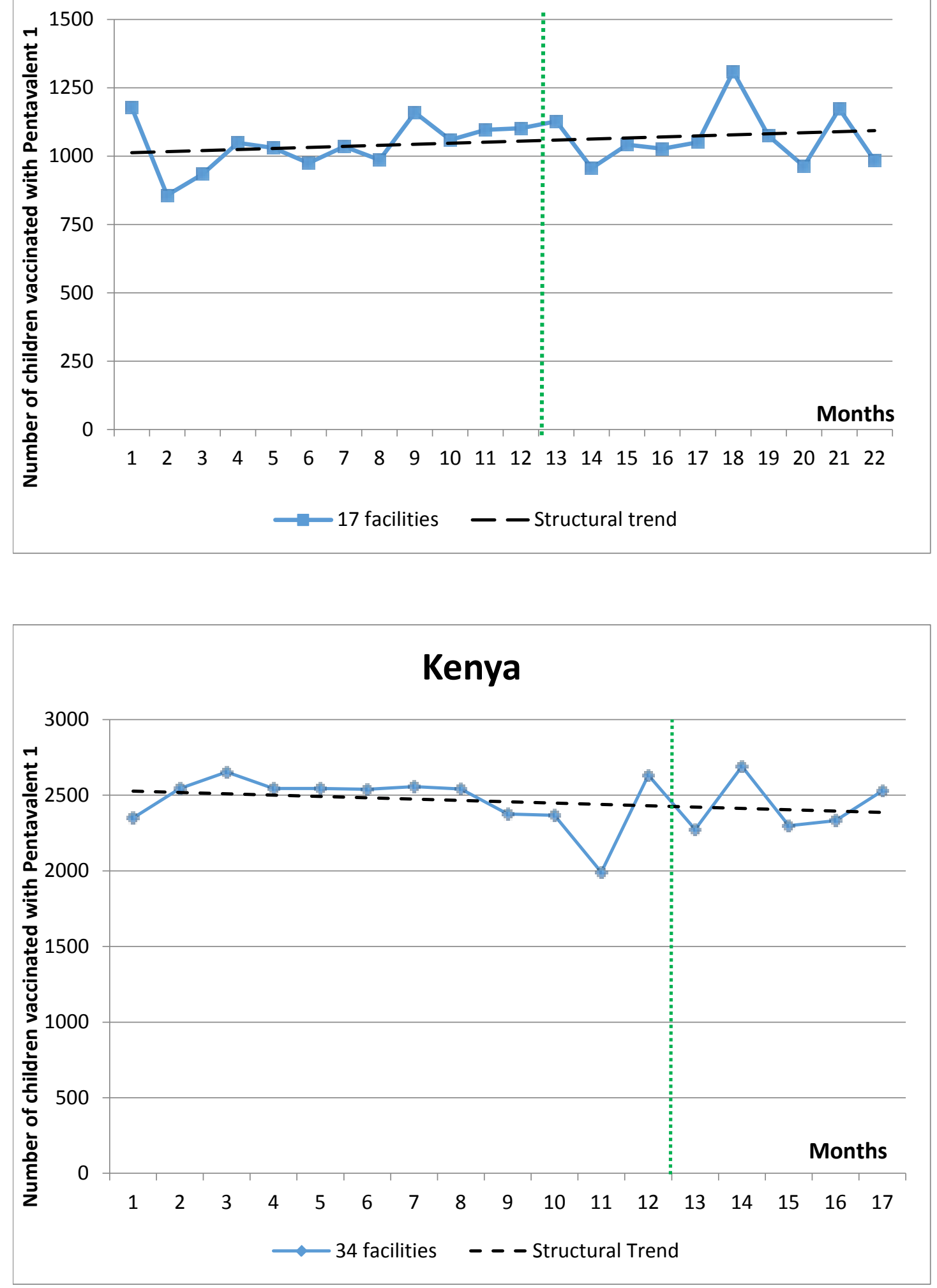


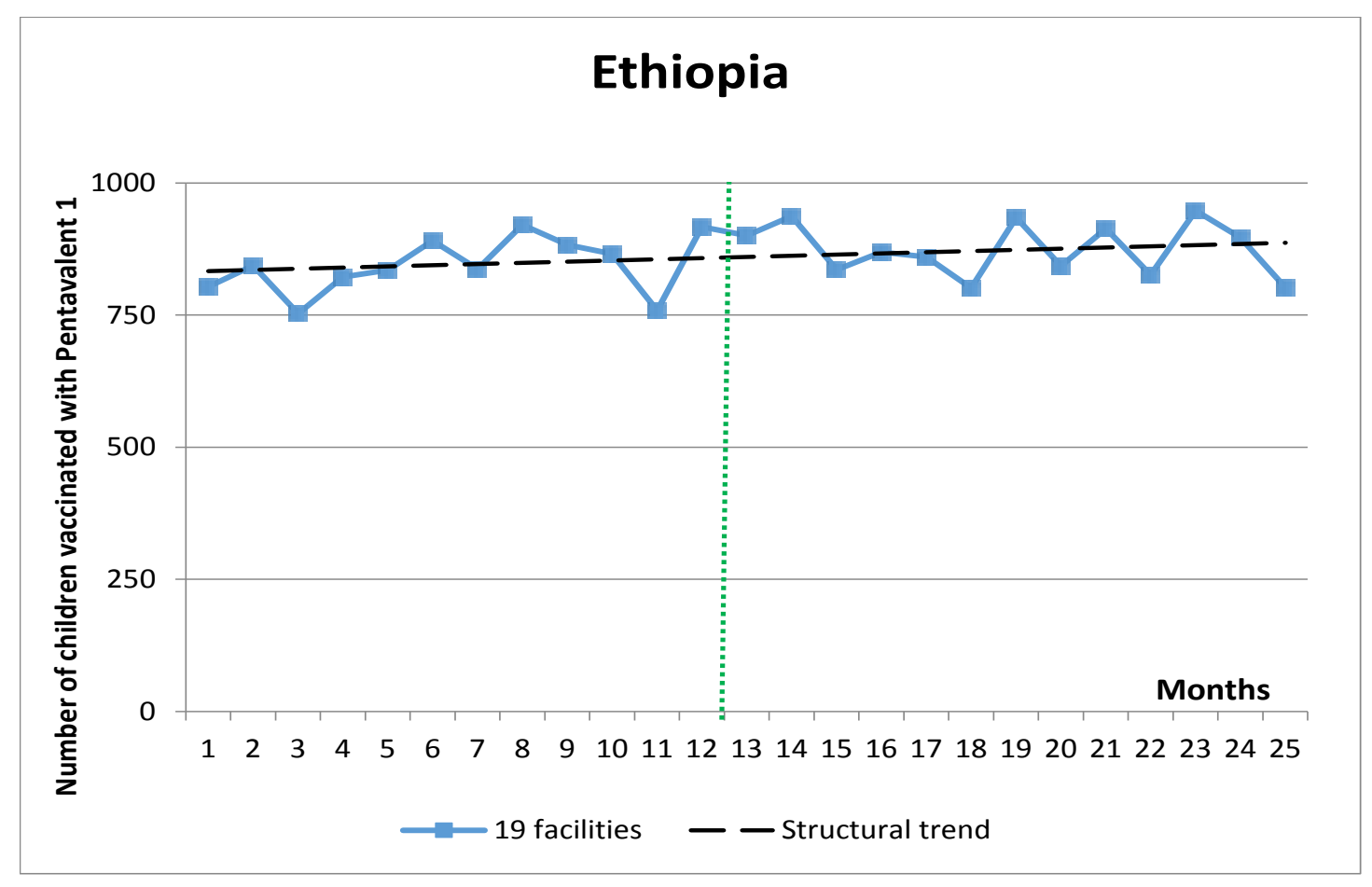

Messages were said to have focused narrowly on PCV in Cameroon and Ethiopia while addressing wider benefits of vaccination in Kenya and Mali. Facility staff reported strong parental acceptance of PCV in all countries because pneumonia was known and feared. Health worker and parental concerns about injecting the child with both pentavalent and PCV in the same visit were reported at the time of introduction, but subsided rapidly.

\section{Staff morale}

All countries reported increased staff morale resulting from the PCV introduction; the expected decrease in pneumonia was considered a motivational factor.

\section{Discussion}

Our findings show remarkable consistency across the four countries. PCV was generally well integrated into existing routine immunisation programmes. Overall no impact was seen on most aspects of health system inputs, although some positive effects were reported on staff skills and the availability of financial resources. Some temporary negative effects were reported on staff workload and cold chain. Generally no effect was reported on health system management, although there were some country-specific positive effects in disease prevention integration and regulatory procedures. Service delivery largely remained unchanged. There was generally no effect on health system performance, al- though some positive effects on staff morale and AEFI surveillance were reported.

There was a perception in all four countries that the new vaccine enhanced the coverage of other vaccines. However, routine data did not confirm any lasting change in vaccination coverage. This is in line with previous findings on the impact of pentavalent vaccine on vaccination coverage ${ }^{12}$. Perceptions of increased uptake might have been observed because catch-up strategies were deployed in Kenya, Ethiopia and in some regions of Cameroon where the target population had been unclear, meaning that more children had come to be vaccinated for PCV in the period immediately after introduction. The main differences between Mali and other countries were that it had a phased introduction and involved no catch-up strategy.

Similarities between the four countries may reflect common goals in their EPIs, a shared Gavi Alliance application processand standard introduction preparations. Stronger emphasis was placed on a more integrated approach to pneumonia prevention and control in Ethiopia, where child health and vaccination activities were incorporated into each geographical directorate of the Ministry of Health, leading to more integrated activities. It has previously been argued that without more emphasis on other strategies to combat pneumonia beyond vaccination, countries will not achieve expected reductions in child mortality ${ }^{23}$. 
Limited or no effects were seen in programme areas that received no additional funding and/or were left out of technical planning. These included changes in delivery models and general collaborative activities beyond EPI (e.g. integrated approach to pneumonia control, co-delivery of interventions). These findings suggest that if policymakers want to see greater positive impacts of introducing new vaccines, more long-term engagement, collaboration and financing ${ }^{13,24}$ is needed. It is unlikely that a new vaccine introduction, which is focused on achieving targeted high population coverage, may foster such structural changes, unless a deliberate strategy is developed. Those hoping to use introductions as opportunities to strengthen EPI should consider this in the early planning stages of introduction, as outlined by WHO in their recently updated guidance on new vaccine introductions ${ }^{25}$.

Although our findings suggest that there were no longterm negative effects to the PCV introduction, questions remain about the limits of health systems to absorb new interventions. As new vaccine introductions continue apace, further research will be needed to better gauge the limits of the systems' absorptive capacities.

\section{Strengths and limitations}

This study used several methods, enabling triangulation of findings. This was particularly useful in the case of pentavalent vaccine coverage. However the study was also limited by poor quality, or absent, routine data and the inability to gather post-introduction data for a full year in all countries. These findings might not be generalisable for all vaccine introductions; effects of introductions depend on the delivery methods, target populations and general context of the EPI and health system.

Data collection tools were structured around the WHO's health systems building blocks framework. Although advantageous for its wide scope, the framework lacks a health services demand component ${ }^{19}$. This study focused on the impact on the health system and did not include the impact of PCV introductions on communities' acceptance and perceptions of other vaccines or confidence in the health system. Further work in this area is needed.

\section{Conclusion}

The introduction of PCV had no overall effect on the EPI or health system levers. However there were some positive effects, such as a boost to staff morale, staff training and financial resource availability. Although there were some negative impacts, such as increased workload, these tended to be only temporary. This lack of long-term negative impacts is noteworthy, given previous questions about the risks of overburdening already weak health systems. The greatest effects were felt in areas with either planning activities and/or investments. Those hoping for greater positive impacts of new vaccine introductions should use the planning process to leverage broader approaches that may lead to greater effects both within and beyond EPI.

\section{Acknowledgements}

Funding for this study was received from the Bill and Melinda Gates Foundation (Grant number OPP51822). The authors would like to thank all the in-country collaborators and data collectors, the respondents and participants of the study, as well as Dr. Mylene Lagarde for her help with routine data analysis.

\section{Conflict of interest disclosure}

None of the authors state any existing conflicts of interest.

\section{References}

1. Walker CL, Rudan I, Liu L, Nair H, Theodoratou E, Bhutta ZA, et al. Global burden of childhood pneumonia and diarrhoea. Lancet. 2013;381(9875):1405 PubMed -16 .

2. McIntosh K. Community-acquired pneumonia in children. N Engl J Med. 2002;346(6):429 PubMed -37.

3. Thigpen MC, Whitney CG, Messonnier NE, Zell ER, Lynfield R, Hadler JL, et al. Bacterial meningitis in the United States, 1998-2007. N Engl J Med. 2011;364(21):2016 PubMed -25.

4. Grijalva CG, Nuorti JP, Arbogast PG, Martin SW, Edwards KM, Griffin MR. Decline in pneumonia admissions after routine childhood immunisation with pneumococcal conjugate vaccine in the USA: a time-series analysis. Lancet. 2007;369(9568):1179-86.

5. Ayieko P, Griffiths UK, Ndiritu M, Moisi J, Mugoya IK, Kamau T, et al. Assessment of health benefits and cost-effectiveness of 10-valent and 13-valent pneumococcal conjugate vaccination in Kenyan children. PLoS One. 2013;8(6): PubMed e67324.

6. World Health Organization position paper. Pneumococcal conjugate vaccine for childhood immunisation. Wkly Epidemiol Rec. 2007;82:93-107 PubMed .

7. GAVI Alliance. Pneumococcal Vaccine Support 2014 [cited 20141 December]. Available from: http://www. gavi.org/support/nvs/pneumococcal/.

8. Berhane Y, Worku A, Demissie M, Tesfaye N, Asefa N, Aniemaw W, et al. Children who received PCV- 
10 vaccine from a two-dose vial without preservative are not more likely to develop injection site abscess compared with those who received pentavalent (DPTHepB-Hib) vaccine: a longitudinal multi-site study. PLoS One. 2014;9(6):e97376.

9. Ben-ShimolS, Greenberg D, Givon-Lavi N, Schlesinger Y, Somekh E, Aviner S, et al. Early impact of sequential introduction of 7-valent and 13-valent pneumococcal conjugate vaccine on IPD in Israeli children $<5$ years: an active prospective nationwide surveillance. Vaccine. 2014;32(27):3452 PubMed -9.

10. Harboe ZB, Dalby T, Weinberger DM, Benfield T, Molbak K, Slotved HC, et al. Impact of 13-valent pneumococcal conjugate vaccination in invasive pneumococcal disease incidence and mortality. Clin Infect Dis. 2014;59(8):1066 PubMed -73.

11. Hortal M, Estevan M, Meny M, Iraola I, Laurani H. Impact of pneumococcal conjugate vaccines on the incidence of pneumonia in hospitalized children after five years of its introduction in Uruguay. PLoS One. 2014;9(6): PubMed e98567.

12. Shearer JC, Walker DG, Risko N, Levine OS. The impact of new vaccine introduction on the coverage of existing vaccines: a cross-national, multivariable analysis. Vaccine. 2012;30(52):7582 PubMed -7.

13. Wang S, Hyde T, Mounier-Jack S., Brenzel L, Favin M, Gordon S, et al. New vaccine introductions: Assessing the impact and the opportunities for immunization and health systems strengthening. Vaccine 2013;31S (2013) (B122- B128).

14. WorldHealth Organisation/UNICEF. Global action plan for prevention and control of pneumonia (GAPP). 2009.

15. Burchett HED, Mounier-Jack S, Torres-Rueda S, Griffiths UK, Ongolo-Zogo P, Rulisa S, et al. The impact of introducing new vaccines on the health system: Case studies from six low- and middle-income countries. Vaccine. 2014; 32(48): 6505-6512.

16. World Health Organization. Everybody's business: strengthening health systems to improve health outcomes. WHO's Framework for Action. Geneva: World Health Organization. 2007.

17. World Health Organzation ad hoc working group on impact of new vaccines on health systems. Impact of New Vaccine Introduction on Immunization and Health Systems: Summary of Main Themes and Findings from 5 Data Sources by WHO Health System Building Blocks. April 2012; http://www.who.int/ immunization/sage/meetings/2012/april/1_Summary_Main_Themes_23March.pdf.

18. World Health Organization. The World Health Report 2000 Health Systems: Improving Performance. 2000.

19. Mounier-Jack S, Griffiths UK, Closser S, Burchett HED, Marchal B. Measuring the health systems impact of disease control programmes: a critical reflection on the WHO building blocks framework. BMC Public Health. 2014;14:278.

20. World Health Organization. New Vaccine Post-Introduction Evaluation, (PIE). Geneva: available from http://whqlibdoc.who.int/hq/2010/WHO_ IVB_10.03_eng.pdf, 2010.

21. Umea University. Open Code [Online]. Umea, Sweden: Umea University. Available: http://www.phmed. umu.se/english/divisions/epidemiology/research/ open-code/ [Accessed 08/03/2012]. 2011.

22. Lagarde M. How to do (or not to do) ... Assessing the impact of a policy change with routine longitudinal data. Health Policy Plan. 2012;27(1):76 PubMed -83.

23. Gill CJ, Young M, Schroder K, Carvajal-Velez L, McNabb M, Aboubaker S, et al. Bottlenecks, barriers, and solutions: results from multicountry consultations focused on reduction of childhood pneumonia and diarrhoea deaths. Lancet. 2013;381(9876):1487-98.

24. Hyde TB, Dentz H, Wang SA, Burchett HED, Mounier-Jack S, Mantel CF. The impact of new vaccine introduction on immunization and health systems: a review of the published literature. Vaccine. 2012;30(45):6347 PubMed -58 .

25. World Health Organization. Principles and considerations for adding a vaccine to a national immunization programme: From Decision to Implementation and Monitoring. April 2014; http://apps.who.int/iris/ bitstream/10665/111548/1/9789241506892_eng.pdf.

26. World Bank. World DataBank. 2014.

27. UNICEF/World Health Organization. Pneumonia: The Forgotten Killer of Children. 2006.

28. Global Health Data Repository [Internet]. 2013 [cited 30 Nov 2013]. Available from: http://apps.who.int/ gho/data/node.main.A827. 